\title{
Design and Characterization of Canopy Air Curtain for Protecting Against Diesel Particulate Matter Exposures in Underground Mines
}

James Noll ( $\sim$ jnoll@cdc.gov)

NIOSH: National Institute for Occupational Safety and Health

\section{Randy Reed}

NIOSH: National Institute for Occupational Safety and Health

\section{Drew Potts}

NIOSH: National Institute for Occupational Safety and Health

Mike Shahan

NIOSH: National Institute for Occupational Safety and Health

\section{Research}

Keywords: Diesel Particulate Matter Exposures, Canopy Air Curtain

Posted Date: October 9th, 2020

DOI: https://doi.org/10.21203/rs.3.rs-89151/v1

License: (9) This work is licensed under a Creative Commons Attribution 4.0 International License. Read Full License 


\section{Abstract}

Blasters are one of the highest exposed work groups to diesel particulate matter (DPM) in underground metal/nonmetal mining. These workers can spend a good portion of their day under a canopy in a basket loading blastholes with explosives. Therefore, one way of potentially reducing their exposures to DPM is to place a canopy air curtain (CAC) on the basket of the ANFO loader. In the original design of the CAC on a roof bolting machine and shuttle car, a fan draws in air through a filter to capture the dust and then supplies clean air beneath the canopy where a miner is working. This paper describes the testing of a CAC that was redesigned to fit an ANFO loader and prevent exposures to DPM as well as respirable dust. Laboratory measurements demonstrated reductions of submicron particles that relate to the percent reductions of DPM. The CAC provided substantial protection of mine workers to DPM ( $80 \%$ reductions), from within $15.24 \mathrm{~cm}$ (6 inches) of the edge of the CAC using a 7.62-cm (3-inch) lip. As the mine worker approaches the edges of the CAC, the percent reduction starts to reduce to the $30-50 \%$ range. The mine worker achieves the best results when within $15.24 \mathrm{~cm}$ ( 6 inches) from the edge of the CAC. In addition, the CAC should be located such that the breathing zone of the mine worker is $25.4-50.8 \mathrm{~cm}(10-20$ inches) below the CAC.

\subsection{Introduction}

Exposure to diesel exhaust has been linked to various adverse health outcomes [1, 2]. In 2012, the International Agency for Research on Cancer (IARC) categorized diesel engine exhaust as a carcinogen to humans (Group 1) [3]. Exposure to diesel particulate matter (DPM) is especially concerning for underground miners. Since underground miners work alongside diesel equipment in a confined environment, they can be exposed to some of the highest levels of diesel exhaust in the U.S [4-7]. Therefore, the Mine Safety and Health Administration (MSHA) promulgated a rule to limit exposures of metal/nonmetal underground miners to DPM to an eight-hour time-weighted average (TWA) of $160 \mu \mathrm{g} / \mathrm{m}^{3}$ total carbon (TC) [6, 7]. This compliance limit is based upon feasibility of compliance with the goal being to reduce a carcinogen, in this case DPM, to the lowest levels possible.

Since this rule went into effect, DPM exposures in mining have decreased, but they are still above levels of other occupations in other industries, such as agriculture, construction, manufacturing, etc., and in some cases above the personal exposure limit (PEL) for mining $[5,8]$. A review of MSHA compliance data between 2009-2014 shows that approximately $20-25 \%$ of underground miners are out of compliance each year. Further analysis shows that $46 \%$ of the out-of-compliance samples are from blasters, load haul dump drivers, and scalers, with blasters being one of the highest exposed professions in mining. Workers in these professions usually work outside of cabs in areas where diesel equipment is operating. The average DPM exposures for blasters are about $156 \mu \mathrm{g} / \mathrm{m}^{3} \mathrm{TC}$, with exposures at times above $500 \mu \mathrm{g} / \mathrm{m}^{3}$ TC. Mines can have a difficult time ventilating the areas due to the large energy requirements to move air through the large underground openings where these miners commonly work. Some mines use administrative controls to avoid miners' exposure to DPM by having them work on off-schedules or upstream of diesel vehicles [9]. However, these types of solutions are not always feasible or practical. 
Blasters can spend a substantial amount of their time at the face loading explosives into blastholes. The face can be quite large, requiring the use of a high lift. The ANFO loader is a machine that incorporates a high lift where a canopy is usually located above the mine worker. Therefore, one potential control technology to help reduce their exposures may be using the canopy air curtain (CAC) attached to the canopy of the ANFO loader.

As demonstrated in Fig. 1, the CAC delivers clean air over the operator's breathing zone. A fan draws in air through a filter to capture the dust and then supplies clean air beneath the canopy where a miner is working. The development of the canopy air curtain (CAC) dates back to the $1970 \mathrm{~s}$, starting with the initial development of the CAC by the Donaldson Company, Inc. under contract from the U.S. Bureau of Mines [10]. This CAC was originally developed for continuous miner operators when continuous mining machines had cabs. The need for a CAC on the continuous miner was eliminated when the cab was removed from the machine design. However, CAC development progressed to include designs for a roof bolting machine to protect roof bolters from respirable coal mine dust [11-13]. The original design of the CAC by the National Institute for Occupational Safety and Health (NIOSH) provided even airflow across the entire canopy and results from laboratory testing demonstrated reductions of respirable dust concentrations ranging from $67-75 \%$ in ventilation airflow ranging from $10-120 \mathrm{fpm}$ [11].

Fletcher Mining Co. incorporated the CAC into their roof bolting machines but revised the design to have the airflow just around the perimeter of the canopy. Laboratory testing showed that this design only reduced the respirable dust concentrations by $17-24 \%$ [13]. In order to increase its effectiveness, Fletcher re-designed the air canopy based upon recommendations from NIOSH to provide airflow over the entire canopy, using a staggered perimeter airflow design with a higher flow rate that prevented contaminated air from entering the CAC protection zone. Laboratory testing demonstrated that this change increased the reduction from $17-24 \%$ to approximately $50 \%$ [14]. Field testing the roof bolter CAC in underground coal mines with this design showed respirable dust reductions ranging from $3-60 \%$ [15]. The variations in respirable dust reduction were due to differing ventilation airflows, differing heights the canopy was above the operator, differing times the operator actually worked underneath the CAC, and the low respirable dust concentrations encountered during the study.

The next step was to redesign the CAC for shuttle cars. This CAC is square in shape and utilizes uniform airflow across the canopy. Laboratory testing at NIOSH demonstrated reductions in respirable dust with different ventilation rates ranging from $74-83 \%$ at a ventilation rate of $0.61 \mathrm{~m} / \mathrm{s}(120 \mathrm{fpm}), 39-43 \%$ at a ventilation rate of $2.0 \mathrm{~m} / \mathrm{s}(400 \mathrm{fpm})$, and $6-16 \%$ at a ventilation rate of $4.3 \mathrm{~m} / \mathrm{s}(850 \mathrm{fpm})$. The higher the interference ventilation airflow, the lower the percent reduction in respirable dust [16].

\subsection{Design of Diesel CAC for ANFO Loader}

Since the CAC is successful for reducing respirable dust exposures, it was thought that it could be used to prevent DPM overexposures. The basic design of the shuttle car CAC was modified by researchers to use on an ANFO loader. However, there are some extra challenges when trying to reduce DPM instead of dust. The particles of DPM are smaller (submicron and nanometer) than dust particles (greater than 1 micron) 
and act more like a gas than particles. Therefore, one of the first adjustments is for the filtration system to capture submicron particles. A MERV 13 filter is currently used in the CAC for shuttle cars, but this filter is only designed to capture $50-75 \%$ of submicron particles. This capture efficiency is too low. Therefore, the initial tests were performed with a higher-rated filter: MERV 16. A MERV 16 rated filter was selected based upon past experience [17-19]. Higher-rated filter media such a HEPA grade can increase backpressure resulting in decreased airflow and induce leaks around the filter, thereby reducing the amount of protection from DPM to the miner. The MERV 16 rated filter has the ability to capture DPM particles at a high efficiency, while still allowing the required airflows to prevent contaminated air from entering the miner's breathing zone. MERV 16 filters are designed to reduce submicron and nanometer particles by over $95 \%$ and have been shown to be effective for use in enclosed cabs [17-19].

Since blasters are one of the highest DPM-exposed working groups in mining, the CAC was designed to filter DPM and fit onto an ANFO loader. A diesel CAC was developed using the plenum design based on the one developed for the shuttle car CAC as seen in Fig. 2. This CAC was rescaled to fit under the canopy of an ANFO loader. This was accomplished by fabricating two $0.91-\mathrm{m}$ by $0.91-\mathrm{m}$ (3-ft by $3-\mathrm{ft}$ ) plenums, each with a series of openings at uniform spacing. Each plenum contains its own blower (rated at 1,800 $\mathrm{cfm}$ ) and operates independently. Both plenums would be attached side by side on the canopy of the ANFO loader to cover the whole area of the ANFO platform/basket. The diesel CAC was designed to produce airflow similar to the shuttle car CAC $(1.16 \mathrm{~m} / \mathrm{s}$ at the borehole). Besides the size, there were a few other modifications from the shuttle car CAC. The shuttle car CAC was fabricated from metal, but the diesel CAC was made from a durable flame-retardant plastic for lighter weight. As mentioned earlier, the filtration was another difference in the diesel CAC, for a MERV 16 filter was used instead of the MERV 13. The blower passes air through a V-bank filter setup with a MERV 16 filter and $15.24 \mathrm{~cm}$ (6 in) tubing into the CAC.

\subsection{Evaluation Methods}

The ANFO diesel CAC was evaluated in the lab at NIOSH Pittsburgh. The evaluation included the measurement of airflow and particle counts underneath the CAC. For measuring the airflow, this analysis included measuring the airflow across the plenum including at three different heights $(25.4,50.8$, and $76.2 \mathrm{~cm}$ ) below the CAC to determine how rapidly the airflow may decrease. Reed et al. 2019 [14] demonstrated that the airflow and reductions in dust concentrations will start to decrease as one is farther from the CAC. Therefore, three distances below the CAC were measured to determine the location of the CAC in reference to the mine worker which provides protection from DPM. Then, to determine potentially how well the CAC could reduce DPM exposures, the number of particles measured outside of the CAC and the number measured under the CAC were recorded. These measurements were completed at the same distances underneath the CAC used in airflow measurements. These numbers were compared to determine the percent reduction in particles from $0.3-1 \mu \mathrm{m}$ (size range measured by the ARTI/Met One HHPC-6 particle counters) under the CAC. DPM particles are within this size range; therefore, by measuring the percent reductions in these submicron particles, one may obtain a good idea of the reductions in DPM. Measuring particles in the air at this size range has been used in other studies 
to estimate the potential reductions in DPM [20, 21]. For example, Organiscak et al. [20] used the same instrumentation to measure submicron particles to determine filter efficiencies for enclosed cabs, and Potts and Divers [21] measured submicron particles to evaluate the efficiency of the airstream helmet for reducing DPM concentrations.

\subsection{Measuring Airstream Flow}

To determine the air velocity profile of the diesel CAC, a test stand was built to support the CAC as seen in Fig. 3. A measurement grid measuring 91.44 by $91.44 \mathrm{~cm}$ (36 by $36 \mathrm{in}$.) was placed $25.4 \mathrm{~cm}$ (10 in) below the plenum face. The plane of the grid and the plane of the plenum face were parallel to each other. The measurement grid contained $15.24-\mathrm{cm}$ (6-inch) squares numbering 6 to a side. Each square was uniquely identified by letters from front to back from $\mathrm{C}$ to $\mathrm{H}$ (Y-axis) and then from left to right by numbers ranging from 3 to 8 (X-axis). The velocity using a TSI VelociCalc was measured for one minute and averaged in the center of each square, and triplicate measurements were collected at each square. Then, the grid was moved to be $50.8 \mathrm{~cm}$ (20 in) below the canopy, and the velocity measurements were repeated three times. The measurements were completed again at $76.2 \mathrm{~cm}$ (30 in) below the canopy.

The CAC was divided into sections as shown in Fig. 4 with each color representing a quadrant. Since it would be expected for the airflow and protection to be different around the edge compared to the center of the CAC, the edge was divided into six sections and the center was divided into four quadrants. Each section contained three to four $15.24-\mathrm{cm}$ (6-in) squares with all of the central quadrants containing four squares. Measurements for each quadrant were averaged, and then a $95 \%$ confidence limit was calculated using the equation below (Eq. 1) [22].

$$
C I=\text { Mean } \pm \frac{t s}{\sqrt{N}} \quad \cdots \cdots \ldots \ldots \ldots . .(\text { Equation 1) }
$$

$\mathrm{Cl}$ - confidence interval, $\mathrm{t}-\mathrm{t}$ value for degrees of freedom, $\mathrm{s}$ - standard deviation, $\mathrm{N}$ - number of samples

During the analysis of the initial velocity measurements, the velocity profile of the initial designed CAC demonstrated dead spots or areas with no airflow, i.e. nonuniform airflow. It is important that the plenum provide uniform airflow across the protection zone. To accomplish this, a honeycomb screen is located inside the plenum across the inlet into the plenum area. The air passes through the honeycomb system into the plenum to minimize turbulence. During investigation of the cause of nonuniform flow, the plenum was opened to examine the interior (Fig. 5). The honeycomb section across the inlet had a fine mesh screen covering the beginning and ending portions of the honeycomb. Most likely, the screen meshes were installed by the plenum builder in an attempt to force air to the center of the $91.44-\mathrm{cm} \times 5.08-\mathrm{cm}$ (3$\mathrm{ft}$ by 2 -in) inlet. These screens prevented uniform flow as they provided more resistance at the locations they were installed. NIOSH had recommended the honeycomb design at the inlet as it had been determined that uniform airflow would be provided by the wall behind the inlet, which angles from the 15.24-cm (6-in) inlet opening to almost flush with the other side, as shown in past research [23]. The 
mesh screens were removed, and the CAC was tested again for velocity and particle counting. All results show the airflows with the mesh screens removed.

\subsection{Particle Count Measurements}

In addition to velocity measurements, in the center of each grid square under the canopy, the number of submicron particles (size range of DPM) was collected to determine potential reductions in DPM. Two ARTI/Met One HHPC-6 particle counters (Hach Ultra Analytics, Grants Pass, OR) were used to simultaneously sample and record the number of particles under the CAC in the center of a square and outside the CAC particle size concentrations for one-minute periods [19]. These instruments count airborne particles in channels from 0.3 to $1.0 \mu \mathrm{m}$. The test medium was airborne particles present in the ambient air. The instruments used for measuring under and outside of the CAC were then alternated for another test to average out any instrument sampling biases for each test. Triplicate samples were performed in the center of each square. The number of particles from 0.3 to $1 \mu \mathrm{m}$ were summed, and the particles under and outside of the CAC were used to determine the amount of reductions in particles. The tests for each section were averaged, and as with the flow measurements, the $95 \%$ confidence limits were calculated as described in the previous section.

During the analysis of the particle measurements, it was found that the airflow could be optimized to provide more clean air around the edges. This could be achieved by attaching a brattice cloth (thick tarp material) around the edge of the CAC where a 7.62-cm (3-in) lip would extend below the bottom of the CAC. This prevented interference ventilation airflows from impacting CAC performance and it also directed the plenum airflow downward, improving reductions of submicron particles. Again, the velocity and particle counting measurements were performed. In addition, all measurements were collected for each CAC (right and left - described below).

In order to simplify and obtain another view of the effects of adding the lip and distance from the bottom of the CAC, the percent reductions in the center quadrants was averaged and the $95 \%$ confidence limit was calculated as described above.

\subsection{Results And Discussion}

\subsection{Airflows and Reductions of Submicron Particles When 10 inches Below ANFO CAC}

To provide a perspective for the airflow measurements under the CAC, Fig. 6 shows the orientation of the $\mathrm{CAC}$ with respect to the face. Both plenums were evaluated. The front location would be the front of the basket in an ANFO loader if the CAC was attached to the vehicle. The right and left would be from the perspective of an individual facing the ANFO loader. This orientation is used for both velocities and particle reductions.

When reviewing the particle counting data in Fig. 9, the particle reductions in the four central quadrants ranged from $55-78 \%$. The particle reductions in the perimeter sections ranged from $1-59 \%$, which were generally lower than the center. It can be seen that the particle reductions correspond with the air 
velocities emanating from the plenum. The protection of the miner from DPM will depend upon where the mine worker will be positioned. The position of the CAC should be designed to so that the mine worker will be $15.24 \mathrm{~cm}$ ( $6 \mathrm{in})$ from the edge, and in the case of this CAC in the front part. For loading a face with the ANFO loader, the mine workers are usually located in the front of the basket, hence the front of the CAC. How much time the blasters are leaning over the edge or towards the edge of the CAC needs to be determined. While the \% reductions were good, researchers at $\mathrm{NIOSH}$ desired to improve upon these reductions. Therefore, a 7.62-cm (3-in) lip which protruded below the CAC was inserted around the CAC perimeter to improve reductions, especially around the edge.

The 7.62-cm (3-in) lip increased the flow in the front and left edge (Fig. 10). The airflow velocities in the front seemed to equalize, ranging from 0.57 to $1.24 \mathrm{~m} / \mathrm{s}$. The four central quadrant airflow velocities ranged from 0.34 to $1.28 \mathrm{~m} / \mathrm{s}$, which was less than the previous design without the $7.62-\mathrm{cm}$ (3-in) lip. However, the velocities seem to be more uniform than for the old plenum. There were some sections which had low velocity -1 quadrant at $0.34 \mathrm{~m} / \mathrm{s}$ and the right and back sections at 0.11 and $0.24 \mathrm{~m} / \mathrm{s}$. However, this did not affect the protection as seen in a comparison of Fig. 10 (no lip) and Fig. 11 (with lip).

The 7.62-cm (3-in) lip made a significant difference for reductions in particles in the center of the CAC. As seen in Figs. 10 and 12, the reductions in the center quadrants went from $55-78 \%$ to $65-86 \%$. The reductions in all but one of the center quadrants were over $74 \%$ and closer or over $80 \%$ for six out of the eight. This also showed more consistency in the center, for the differences between quadrants in the center was minimized when the 7.62-cm (3-in) lip was added. Around the edge the percent reductions still varied, as the reductions ranged from $7-53 \%$ with high variability or confidence limits in some cases. The position of the CAC should be designed for the mine worker to avoid the edges as much as possible when performing his/her duties.

\subsection{Effect of Distance below CAC}

Reed et al. 2019 [14] demonstrated that the airflow and reductions in dust concentrations will start to decrease as one is farther from the CAC. Therefore, the efficiency of the diesel CAC was measured at different distances from the CAC to determine where the CAC needs to be located pertaining to the mine worker to still provide adequate protection from DPM. Figure 12 shows how the air velocity changes the further below the CAC with the $7.62-\mathrm{cm}$ (3-in) lip, but most changes are not more than $10 \%$. There are not too many drastic changes in flow even as one measures from $25.4 \mathrm{~cm}$ (10 in) to $76.2 \mathrm{~cm}$ (30 in) below the CAC.

However, there are more changes in the CAC with 7.62-cm (3-in) lip percent reductions in submicron particles as seen in Fig. 13. Observing the CAC with the 7.62-cm (3-inch) lip, the reductions in particles decreased as one sampled farther down from the CAC. The average reductions for the center quadrants go from 78 to 69 to 58 as the distance below the CAC is $25.4 \mathrm{~cm}$ (10 in), then $50.8 \mathrm{~cm}$ (20 in), and finally $76.2 \mathrm{~cm}$ (30 in). Mine workers should be as close to the bottom of the CAC plenum as feasible. Being 25.4 to $50.8 \mathrm{~cm}$ (10 to $20 \mathrm{in}$ ) below the CAC seems to provide reduction in the $70-80 \%$ range in the center 
of the CAC. When constructing the diesel DPM on a vehicle, it should be located so that the mine worker is within 20 inches below the CAC.

\subsection{Conclusion}

The particle count results show that the CAC can provide substantial protection from DPM exposure to mine workers (approximately $80 \%$ reduction of submicron particles) when workers are centrally located underneath the CAC which has a 7.62-cm (3-in) lip. As the miner worker approaches within $15.24 \mathrm{~cm}$ (6 in) of the edge of the CAC, the percent reduction reduces to $30-50 \%$ range. The mine worker should attempt to stay within $15.24 \mathrm{~cm}$ ( 6 in) from the edge of the CAC to achieve the best results. In addition, the CAC should be designed to have the breathing zone of the mine worker to be 25.4 to $50.8 \mathrm{~cm}$ (10 to 20 in) below the CAC, for the reductions in submicron particles decreased as the mine worker was farther below the CAC.

\subsection{Limitations}

These reductions are approximations since submicron particles were used to determine them and not an actual atmosphere of DPM.

In addition, this study is laboratory work which is useful for validating control technologies. However, field work is necessary to establish the feasibility of this control technology and to measure reductions in DPM under actual mining conditions. Since it can matter where the mine worker is located under the CAC, installing the CAC on an ANFO loader at a mine and evaluating the reductions as blasters perform their routine is needed to determine the reductions in DPM from the CAC under actual mining conditions and hence the feasibility of this control technology.

\subsection{Disclaimer}

The findings and conclusions in this paper are those of the authors and do not necessarily represent the official position of the National Institute for Occupational Safety and Health (NIOSH), Centers for Disease Control and Prevention. Mention of any company name or product does not constitute endorsement by $\mathrm{NIOSH}$.

\section{References}

1. Vermeulen R. Silverman D, Garshick E, Vlaanderen J. Portengen., Steenland K (2014) Exposureresponse estimates for diesel engine exhaust and lung cancer mortality based on data from three occupational cohorts. Environ Health Pers 122:172-177

2. Peters S, de Klerk N, Reid A. Fritischi L. Musk AW. Vermulen R (2016) Quantitative levels of diesel exhaust exposure and the health impact in the contemporary Australian mining industry. Occup Environ Med 0:1-8. doi:10.1136/oemed-2016-103808 
3. IARC. IARC: Diesel engine exhaust carcinogenic. Press Release $N^{\circ} 213$. International Agency for Research on Cancer. World Health Organization (2012) June 12

4. EPA. Health assessment document for diesel engine exhaust. Prepared by the National Center for Environmental Assessment, U.S. Environmental Protection Agency, Washington, DC, for the Office of Transportation and Air Quality; 2002; EPA/600/8-90/057F. Available from: National Technical Information Service, Springfield, VA; PB2002-107661 < http://www.epa.gov/ncea>.

5. Pronk A. Coble J. Stewart PA (2009) Occupational exposure to diesel engine exhaust: A literature review. J Expo Sci Environ Epidemiol 19(5):443-457

6. 66 Fed (2001) Reg. 27864. Mine Safety and Health Administration: 30 CFR Part 72. Diesel particulate matter exposure of underground coal miners. In: Limit on concentration of diesel particulate matter; final rule. Code of Federal Regulations. U.S. Government Printing Office, Office of the Federal Register, Washington, DC

7. 71 Fed (2006) Reg. 28924. Mine Safety and Health Administration: 30 CFR 57.5060. Diesel particulate matter exposure of underground metal and nonmetal miners. In: Limit on concentration of diesel particulate matter. Code of Federal Regulations. U.S. Government Printing Office, Office of the Federal Register, Washington, DC

8. Noll J. Gilles S. Wu HW. Rubinstein E (2015) The relationship between elemental carbon and diesel particulate matter in underground metal/nonmetal mines in the United States and coal mines in Australia. Journal of Occupational Environmental Hygiene 12(3):205-211

9. Noll J. Patts L. Grau R. Dealing with DPM: Using real-time diesel particulate matter measurements to optimize the implementation of administrative controls, Rock Products March 2015:36-41

10. Krisko WJ. Develop and Test Canopy Air Curtain Devices. USBM Contract Report H0232067, Pittsburgh, PA: US Dept. of the Interior, Bureau of Mines/Donaldson Company, Inc. 1975

11. Listak JM. Beck TW (2012) Development of a canopy air curtain to reduce roof bolters' dust exposure. Min Eng 64(7):72-79

12. Goodman JVR. Organiscak JA Evaluation of methods for controlling silica dust exposures of roof bolters. Transactions of the Society of Mining, Metallurgy, and Exploration (2003) 2002; 312: 133137

13. Reed WR. Joy GJ. Kendall B. Bailey A. Zheng Y (2017) Development of a Roof Bolter Canopy Air Curtain for Respirable Dust Control. Min Eng 69(1):33-39

14. Reed WR. Joy GJ. Shahan M, Klima S, Ross G (2019) Laboratory results of a 3rd generation roof bolter canopy air curtain for respirable coal mine dust control. Int J Coal Sci Technol 6::15-26. doi:10.1007/s40789-019-0237-6

15. Reed WR. Shahan M. Klima S. Ross G, Singh K, Cross R, Grounds T (2019) Field study results of a 3rd generation roof bolter canopy air curtain for respirable coal mine dust control. Int J Coal Sci Technol. doi:10.1007/s40789-019-00280-5

16. Reed WR. Zheng Y. Yekich M. Ross G. Salem A (2018) Laboratory testing of a shuttle car canopy air curtain for respirable coal mine dust control. Int J Coal Sci Technol 5::305-314. doi:10.1007/s40789- 
018-0225-2

17. Noll JD. Cecala A. Organiscak J. Rider J (2014) Effects of MERV 16 filters and Routine Work Practices on Enclosed Cabs for Reducing Respirable Dust and DPM Exposures in an Underground. Limestone Mine Mining Engineering 66(2):45-52

18. Noll JD. Cecala A. Organiscak J (2011) The effectiveness of several enclosed cab filters and systems for reducing diesel particulate matter. SME Transactions 2011 330:408-415

19. Cecala A. Organiscak J. Noll J. Zimmer J. Comparing the Air Quality Inside Enclosed Cabs of Underground Mining Equipment with MERV 16 and HEPA Filters. SME Annual Meeting 2016 Conference Pre-Prints 16-017, February 21-24, 2016, Phoenix, AZ

20. Organiscak J. Cecala A. Noll JD (2013) Field assessment of enclosed cab filtration system performance using particle counting measurements. J Occup Environ Hyg 10(9):468-477

21. Potts JD. Divers EF (1991) Powered dust-filtering helmet reduces exposure to diesel soot. Proceedings of the 3rd symposium on respirable dust in the mine industries, October 17-19, 1990, Pittsburgh, Pennsylvania. Frantz RL, Ramani RV, eds. Littleton, CO: Society for Mining, Metallurgy, and Exploration, Inc., Jan:105-107

22. Skoog D. West D (1986) Analytical Chemistry. Saunders, New York, pp 48-49

23. Loeffler AJ. Perlmutter M Turbulent flow through porous resistances slightly inclined to the flow direction. National Advisory Committee for Aeronautics Technical Note 4221, Cleveland, OH: Lewis Flight Propulsion Laboratory 1958

\section{Figures}

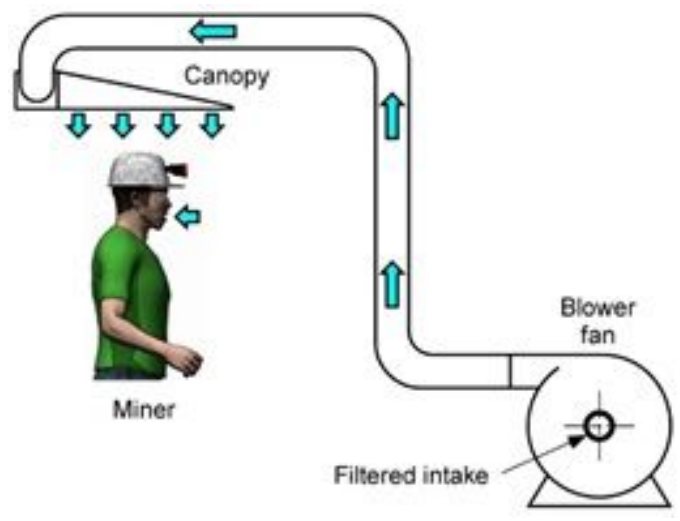

\section{Figure 1}

Schematic of the operation of the canopy air curtain 


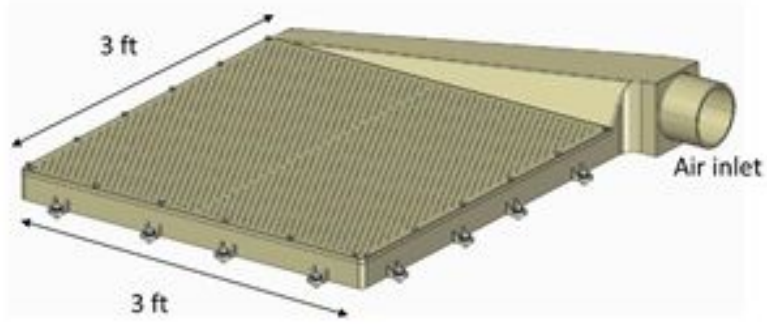

Figure 2

A depiction of one of the canopy air curtain plenums.

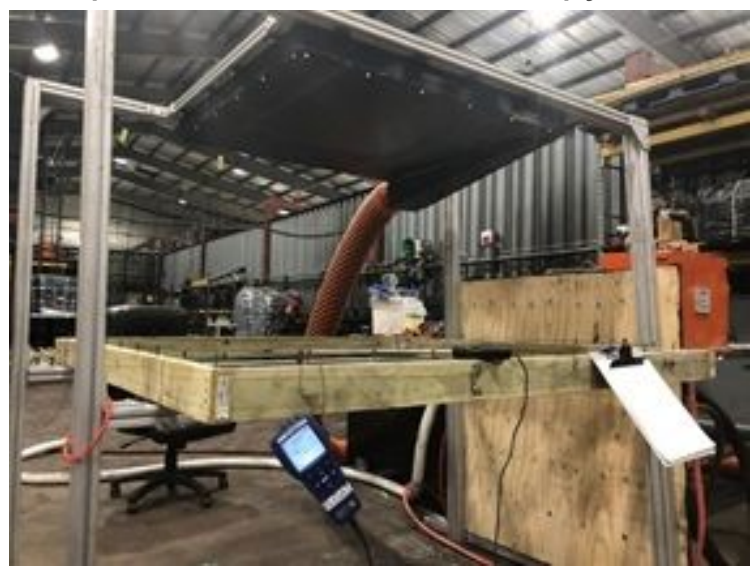

\section{Figure 3}

Picture of one of the canopy plenums for the ANFO CAC design and the grid below to measure the flow and particle counts.

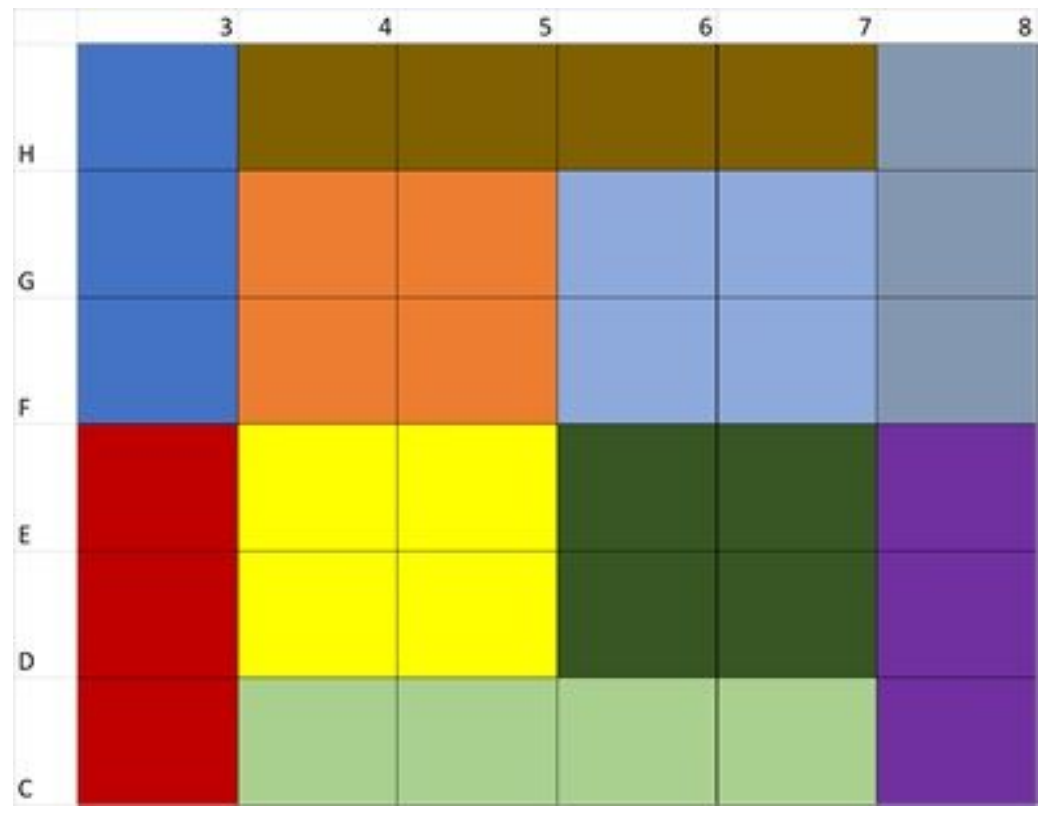

Figure 4 
The grid showing how it was sectioned. Each color is a section of the grid, with the four quadrants located centrally.

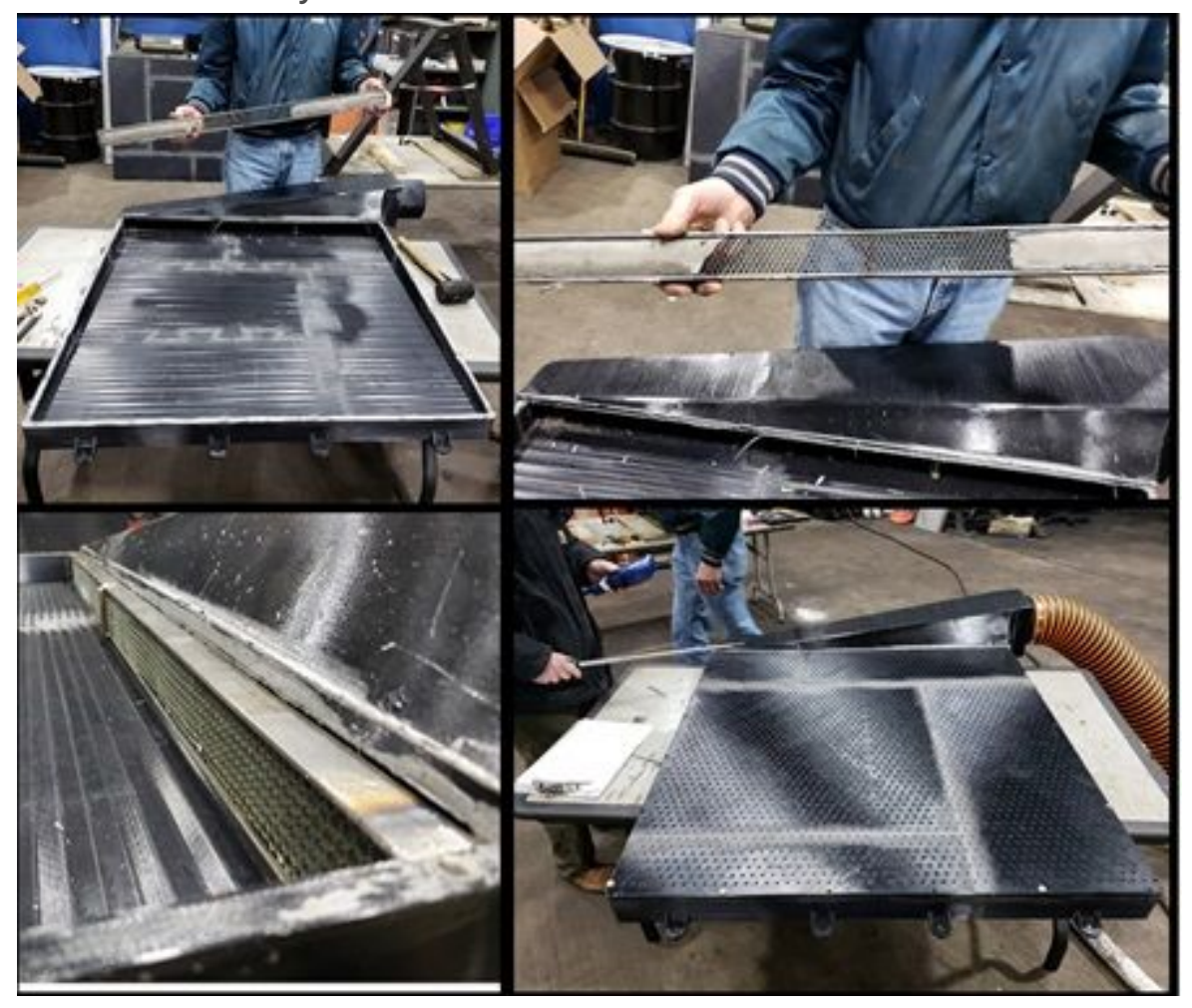

\section{Figure 5}

Opening the canopy plenum to determine cause of nonuniform flow. Upper left shows the plenum with the honeycomb section across the inlet removed. Upper right shows a closeup of the honeycomb section with the mesh screen installed. Lower left shows honeycomb section with mesh screen removed. Lower right shows the assembled plenum.

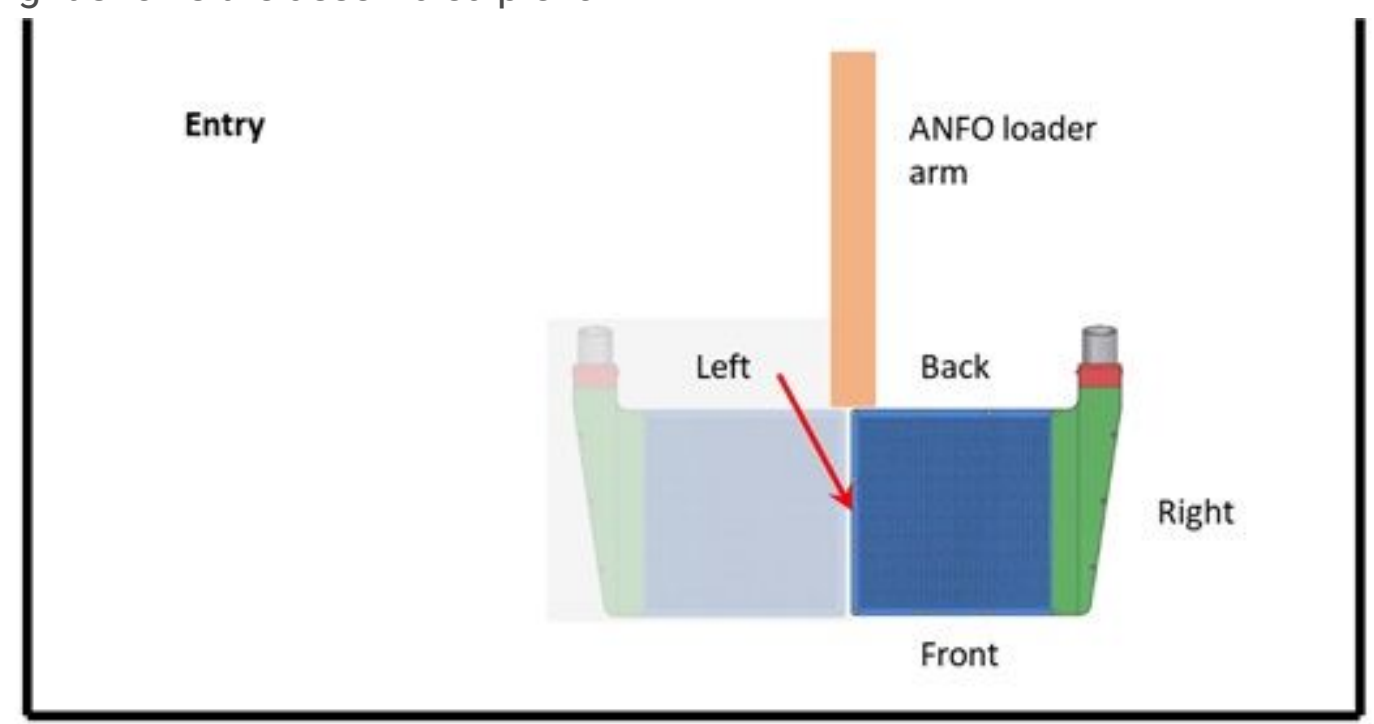

Face

Figure 6 
Depiction of the ANFO loader CAC plenums in the entry. The left side plenum is faded to emphasize the right side plenum.

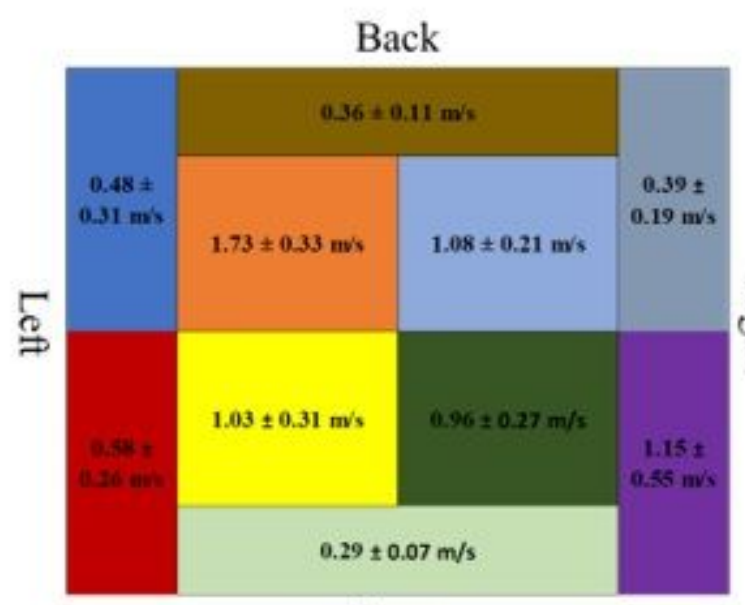

Front

Left Side CAC

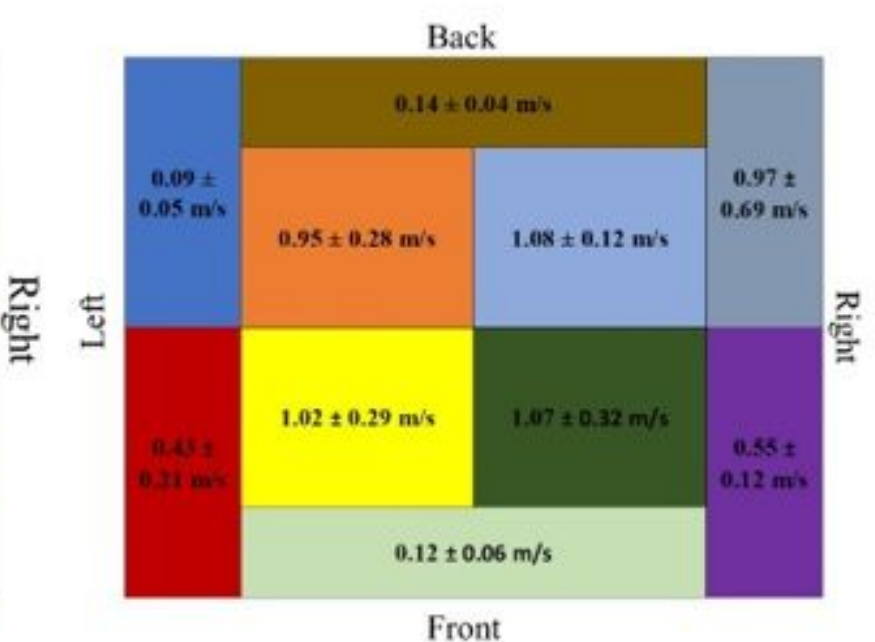

Right Side CAC

\section{Figure 7}

Average air velocity $(\mathrm{m} / \mathrm{s})$ for each section of the plenum.

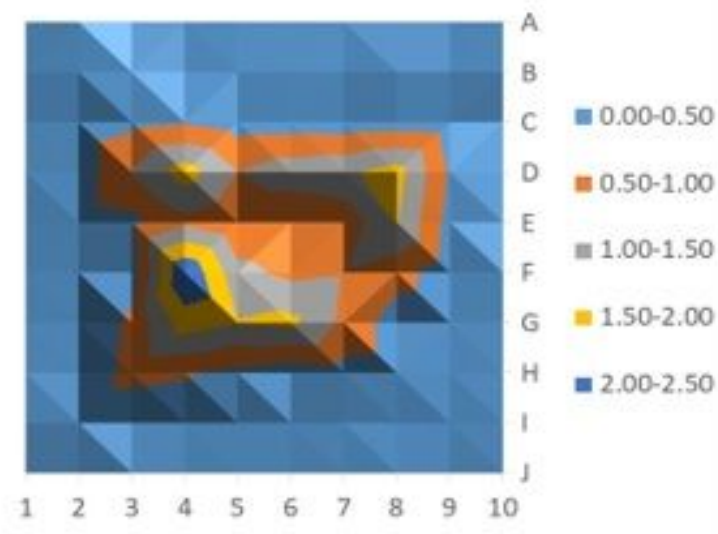

Left Side CAC

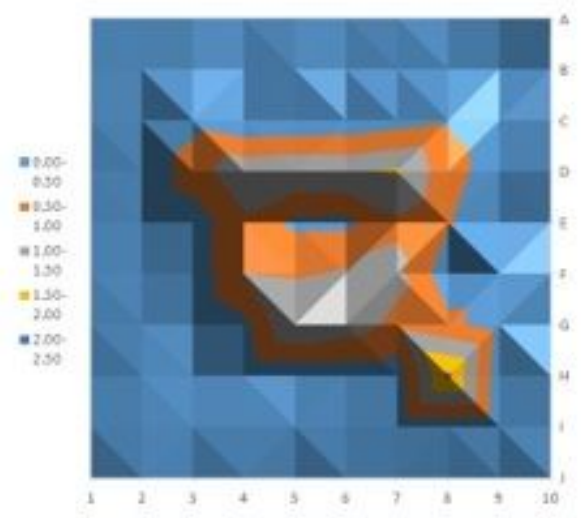

Right Side CAC

\section{Figure 8}

A depiction of the air velocity contours in $\mathrm{m} / \mathrm{s}$ across the plenum. 


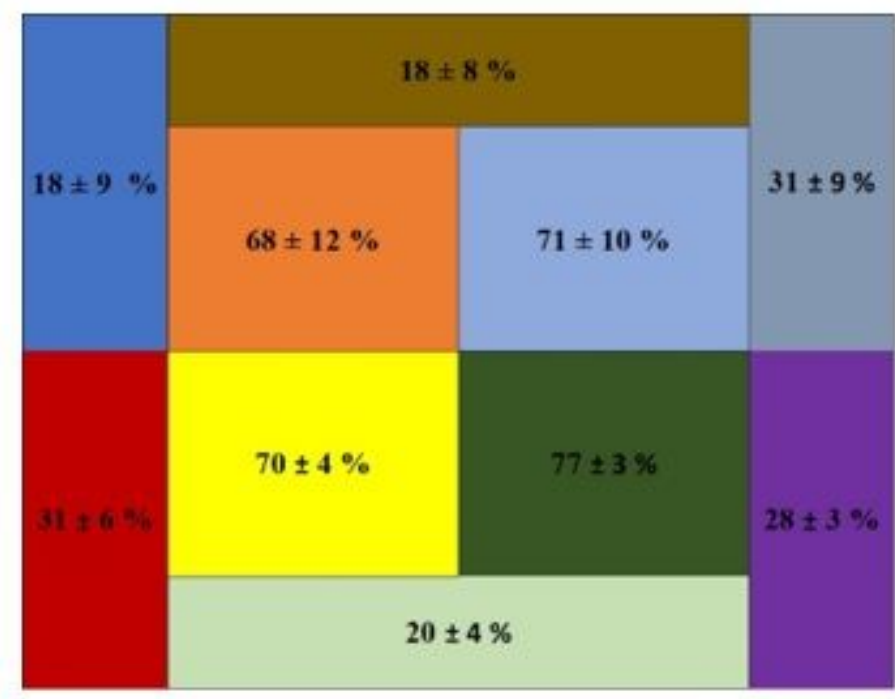

Left Side CAC

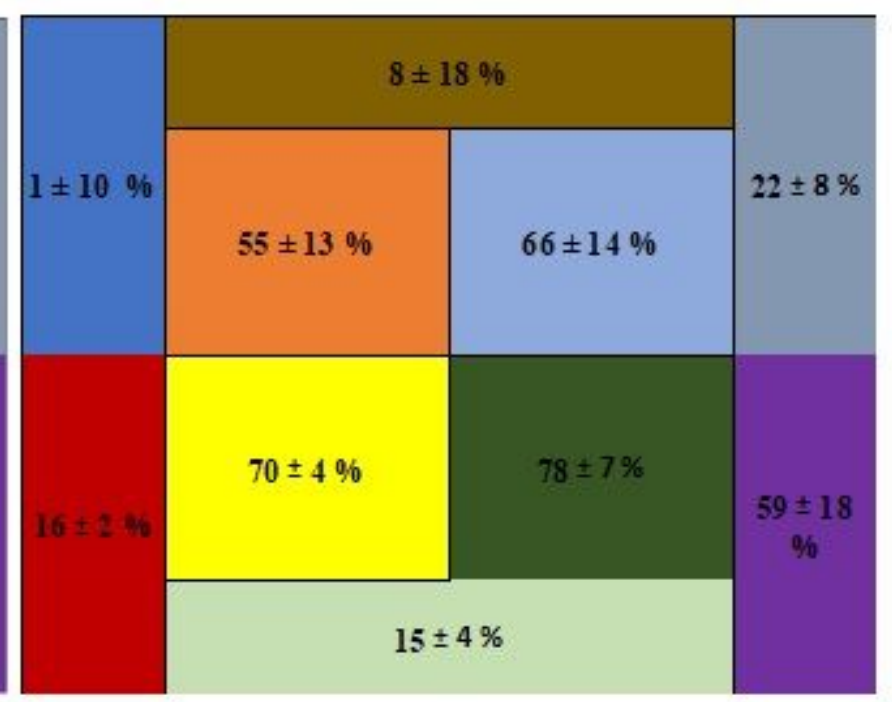

Right Side CAC

\section{Figure 9}

The percent reductions in submicron particles in different sections of the ANFO CAC.

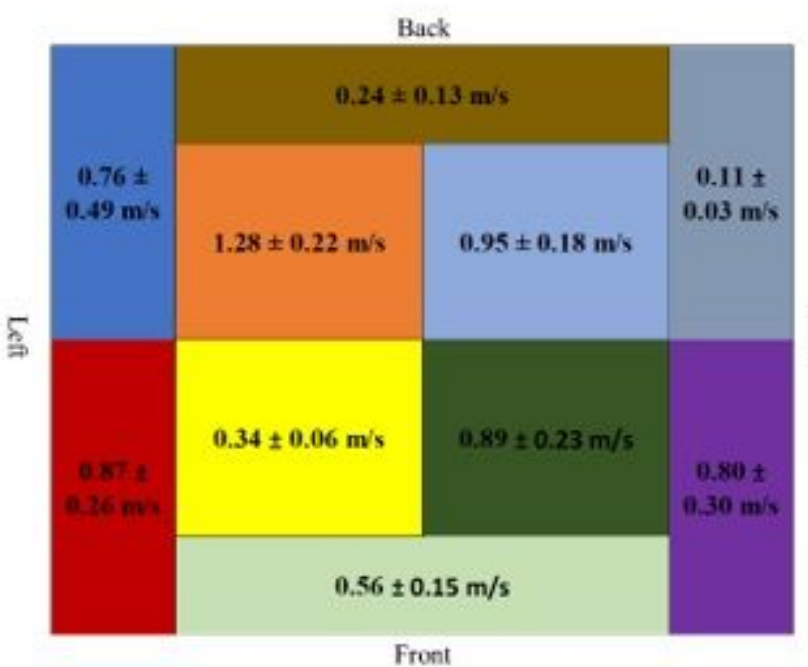

Left Side CAC

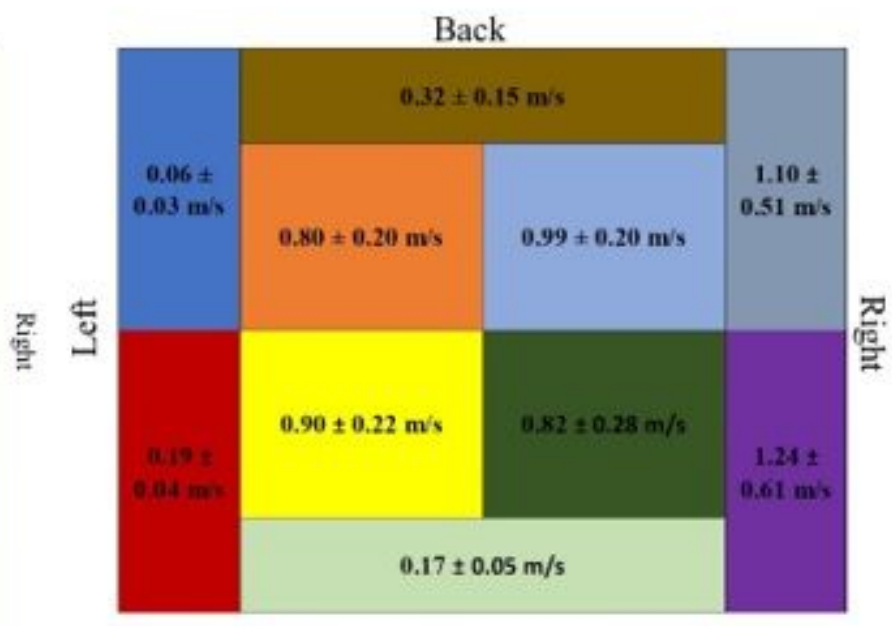

Front

\section{Right Side CAC}

\section{Figure 10}

Average air velocity $(\mathrm{m} / \mathrm{s})$ for each section of the plenum with the 7.62-cm (3-in) lip around the perimeter. 


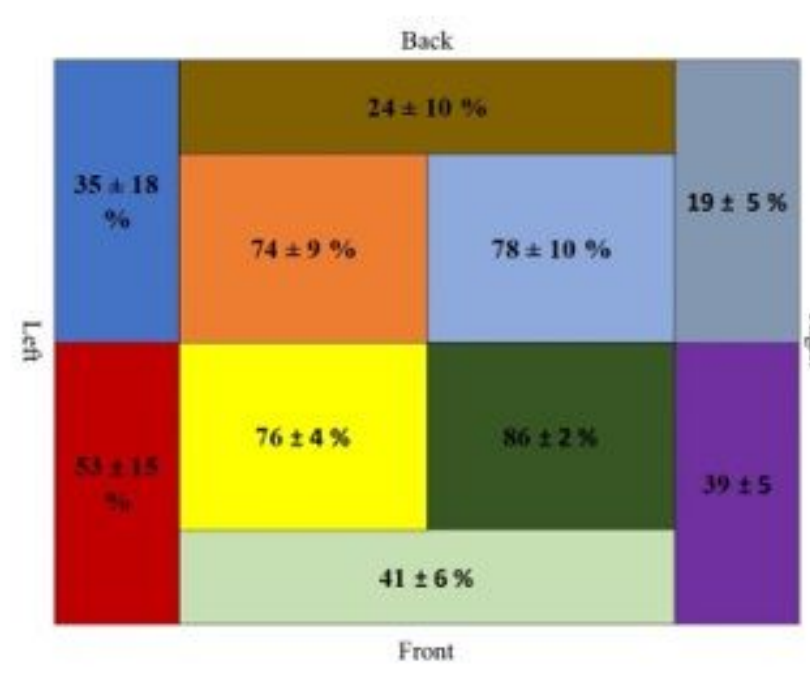

Left Side CAC

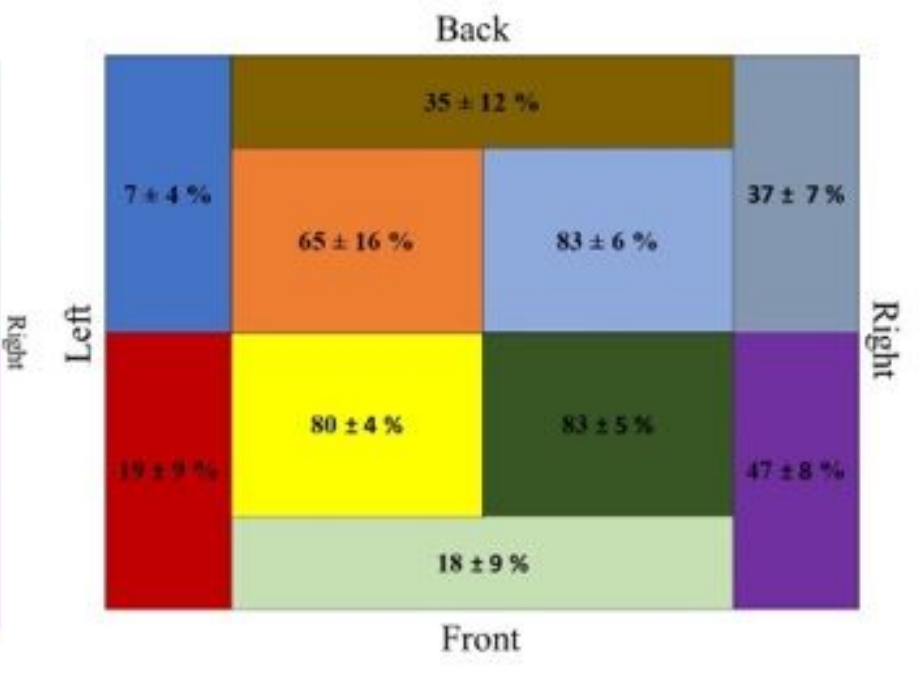

Right Side CAC

\section{Figure 11}

The percent reductions in submicron particles in different sections of the ANFO CAC with the 7.62-cm (3in) lip around the CAC perimeter. 


\section{$25.4 \mathrm{~cm}(10 \mathrm{in})$ below CAC}
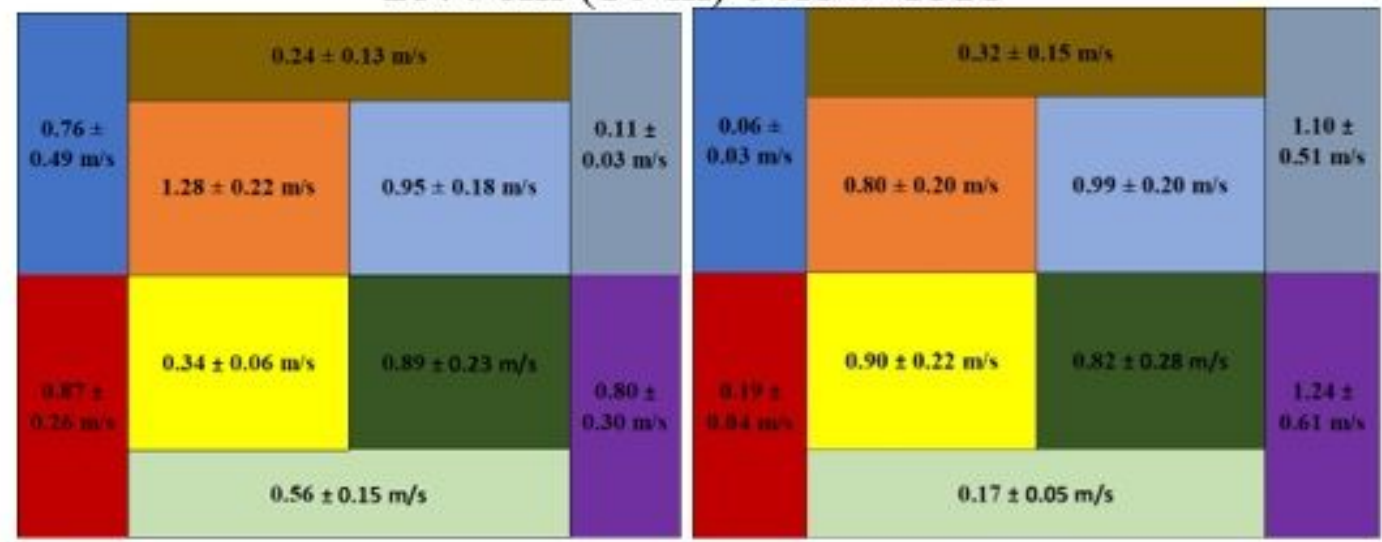

$50.8 \mathrm{~cm}(20$ in) below CAC
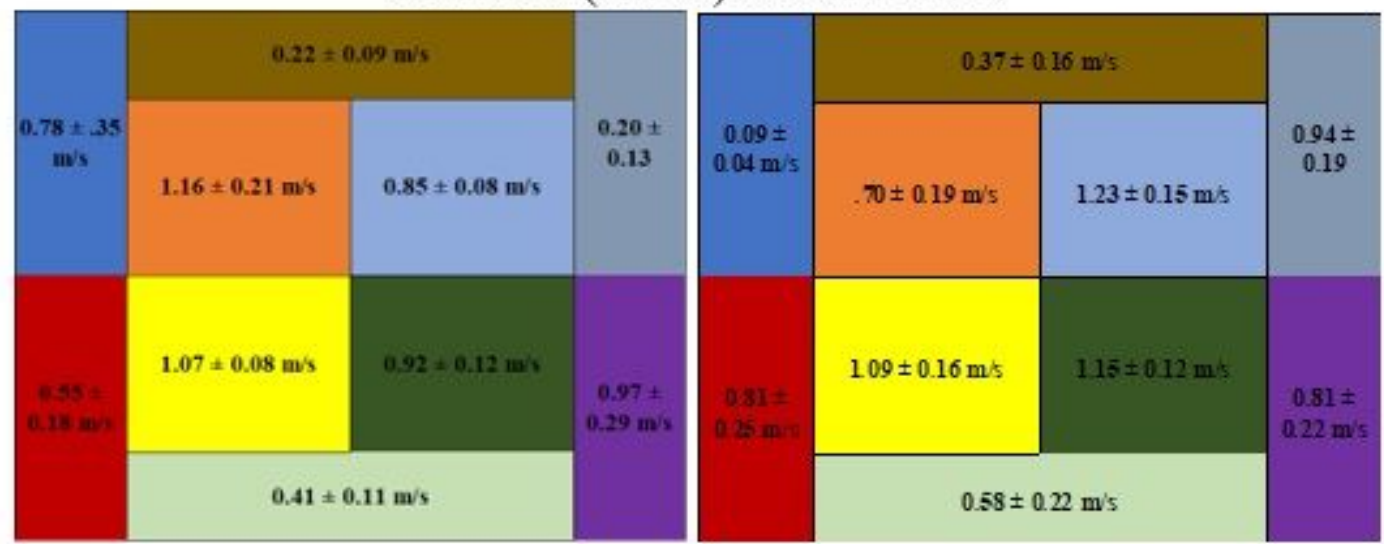

$76.2 \mathrm{~cm}$ (30 in) below CAC

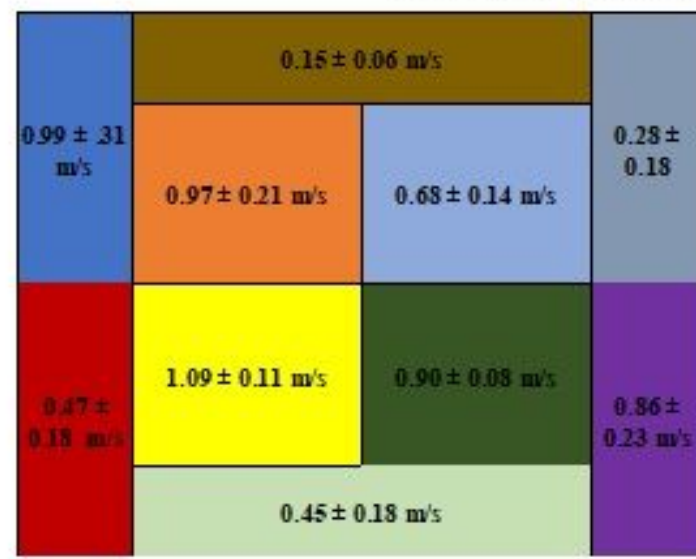

Left Side CAC

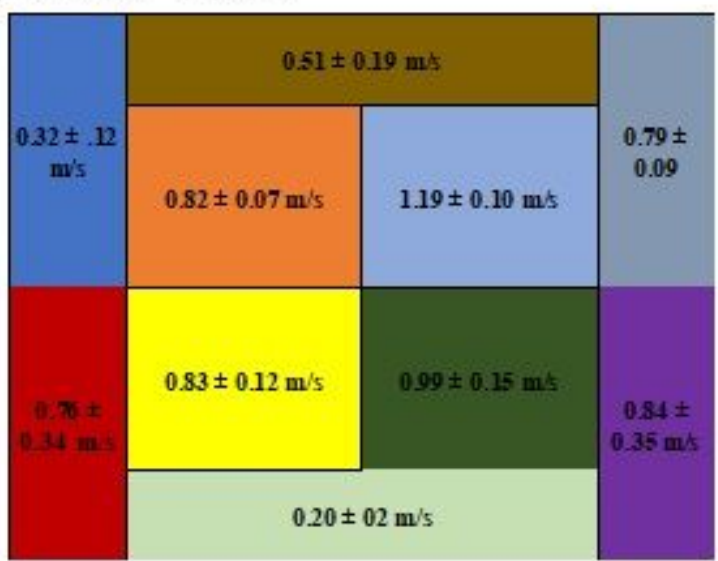

Right Side CAC

\section{Figure 12}

The flow rate in different sections of the ANFO CAC at different distances below the CAC after adding a 7.62-cm (3-in) lip. 


\section{$25.4 \mathrm{~cm}$ (10 in) below CAC}

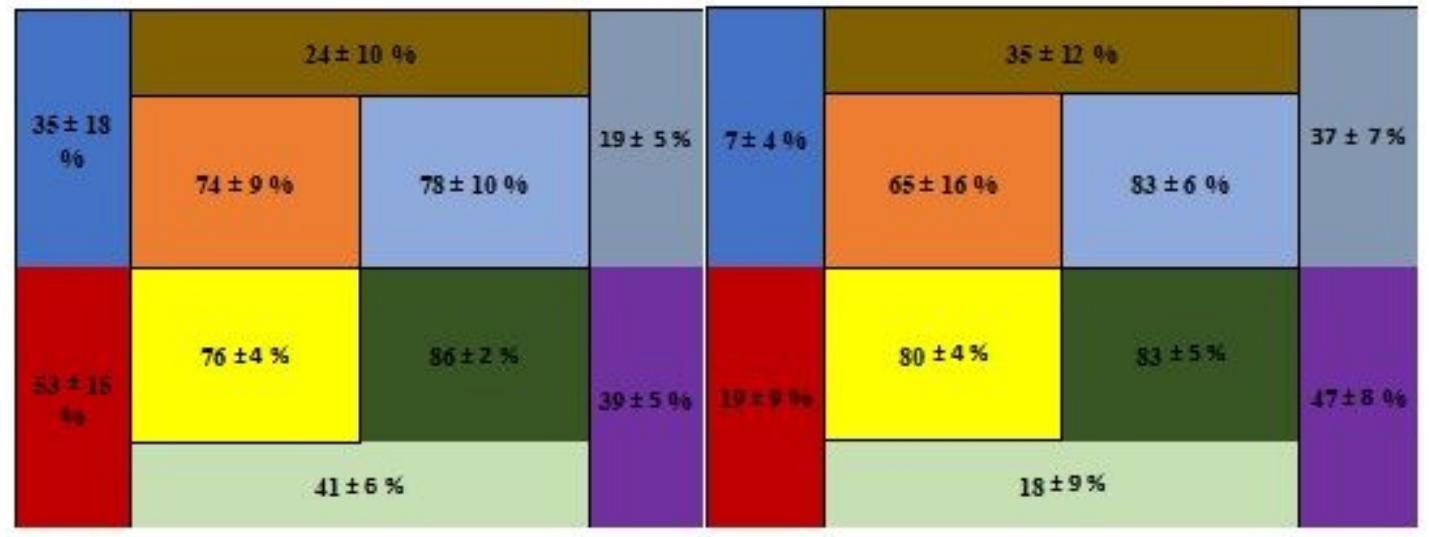

$50.8 \mathrm{~cm}(20$ in) below CAC

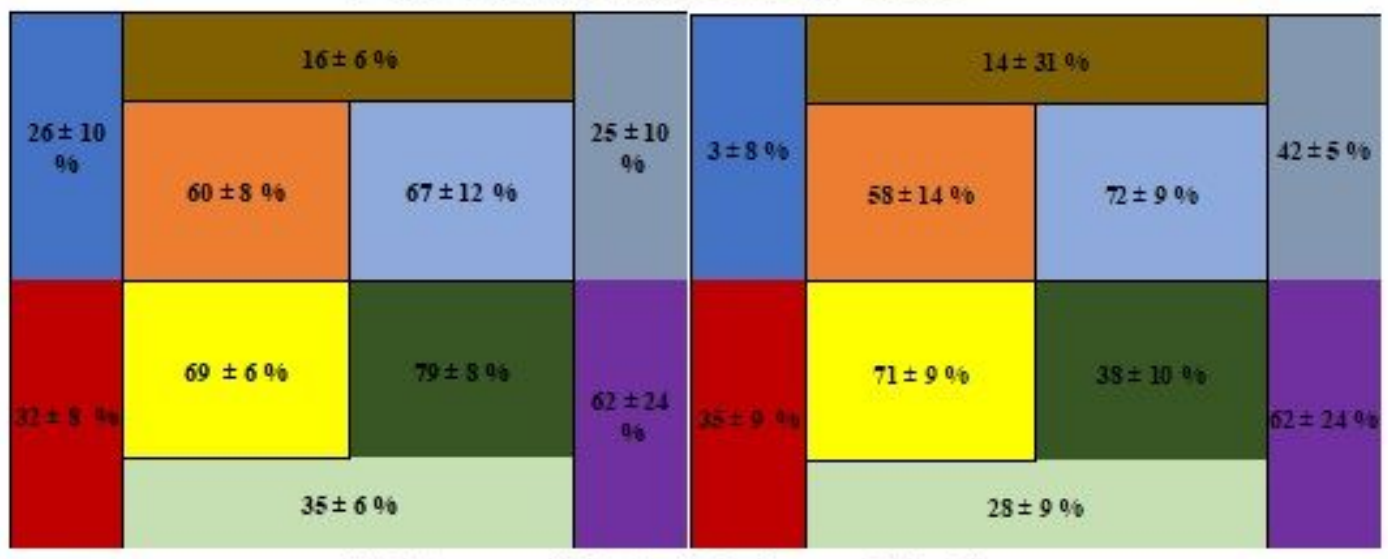

$76.2 \mathrm{~cm}$ (30 in) below CAC

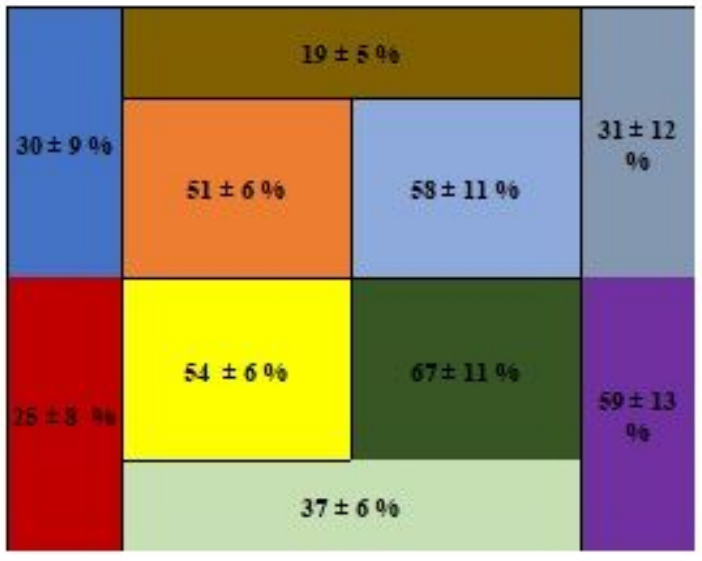

Left Side CAC

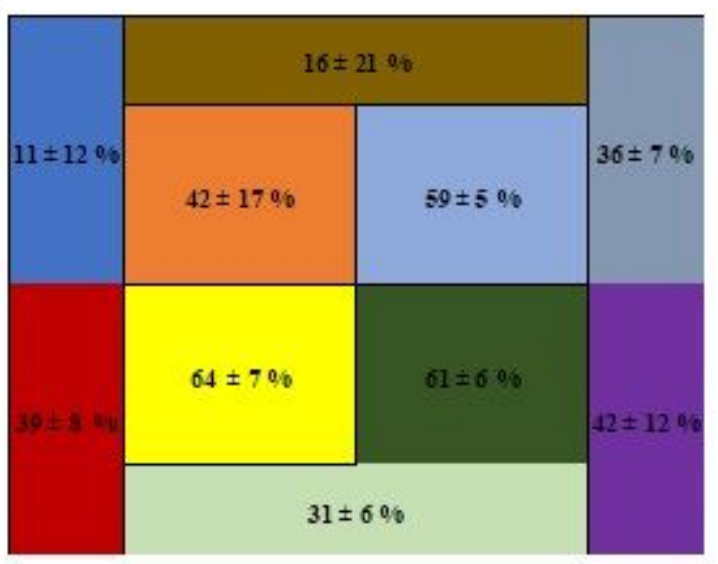

Right Side CAC

\section{Figure 13}

The percent reductions in submicron particles in different sections of the ANFO CAC at different distances from the CAC after adding a 7.62-cm (3-in) lip. 